\title{
The influence of timing of radiation therapy following breast-conserving surgery on 10-year disease-free survival
}

Marissa C van Maaren ${ }^{\star 1,}, 2$, Reini W Bretveld ${ }^{1}$, Jan J Jobsen ${ }^{3}$, Renske K Veenstra ${ }^{4}$, Catharina GM Groothuis-Oudshoorn ${ }^{2}$, Hendrik Struikmans ${ }^{5,6}$, John H Maduro ${ }^{7}$, Luc JA Strobbe ${ }^{8}$, Philip MP Poortmans ${ }^{9,10}$ and Sabine Siesling ${ }^{1,2,10}$

${ }^{1}$ Department of Research, Netherlands Comprehensive Cancer Organisation, PO Box 19079, Utrecht 3501 DB, The Netherlands; ${ }^{2}$ Department of Health Technology \& Services Research, MIRA Institute for Biomedical Technology and Technical Medicine, University of Twente, PO Box 50000, Enschede 7500 KA, The Netherlands; ${ }^{3}$ Department of Radiation Oncology, Medical Spectrum Twente, PO Box 217, Enschede 7500 AE, The Netherlands; ${ }^{4}$ Department of Operations, Medical Research Data Management B.V., PO Box 90, Deventer 7400 AB, The Netherlands; ${ }^{5}$ Department of Radiation Oncology, Haaglanden Medical Center, PO Box 432, The Hague 2501 CK, The Netherlands; ' ${ }^{6}$ Department of Radiation Oncology, Leiden University Medical Center, PO Box 9600 , Leiden 2300 RC, The Netherlands; ${ }^{7}$ Department of Radiation Oncology, University of Groningen, University Medical Center Groningen, PO Box 30001, Groningen 9700 RB, The Netherlands; ${ }^{8}$ Department of Surgical Oncology, Canisius Wilhelmina Hospital, PO Box 9015, Nijmegen 6500 GS, The Netherlands and ${ }^{9}$ Department of Radiation Oncology, Institut Curie, 26 Rue d'Ulm, Paris 75005, France

Background: The Dutch guidelines advise to start radiation therapy (RT) within 5 weeks following breast-conserving surgery (BCS). However, much controversy exists regarding timing of RT. This study investigated its effect on 10-year disease-free survival (DFS) in a Dutch population-based cohort.

Methods: All women diagnosed with primary invasive stage I-IIIA breast cancer in 2003 treated with BCS + RT were included. Two populations were studied. Population 1 excluded patients receiving chemotherapy before RT. Analyses were stratified for use of adjuvant systemic therapy (AST). Population 2 included patients treated with chemotherapy, and compared chemotherapy before (BCS-chemotherapy-RT) and after RT (BCS-RT-chemotherapy). DFS was estimated using multivariable Cox regression. Locoregional recurrence-free survival (LRRFS), distant metastasis-free survival (DMFS) and overall survival (OS) were secondary outcomes.

Results: Population $1(n=2759)$ showed better DFS and DMFS for a time interval of $>55$ than a time interval of $<42$ days. Patients treated with AST showed higher DFS for $>55$ days (hazards ratio (HR) 0.60 (95\% confidence interval (Cl): 0.38-0.94)) and 42-55 days (HR 0.64 (95\% Cl: 0.45-0.91)) than <42 days. Results were similar for DMFS, while timing did not affect LRRFS and OS. For patients without AST, timing was not associated with DFS, DMFS and LLRFS, but 10-year OS was significantly lower for $42-55$ and $>55$ days compared to $<42$ days. In population $2(n=1120)$, timing did not affect survival in BCS-chemotherapy-RT. In BCS-RTchemotherapy, DMFS was higher for $>55$ than $<42$ days.

Conclusions: Starting RT shortly after BCS seems not to be associated with a better long-term outcome. The common position that RT should start as soon as possible following surgery in order to increase treatment efficacy can be questioned.

\footnotetext{
*Correspondence: MC van Maaren; E-mail: m.vanmaaren@iknl.nl

${ }^{10}$ These authors contributed equally to this work.
}

Received 1 February 2017; revised 28 April 2017; accepted 11 May 2017; published online 6 June 2017

(C) 2017 Cancer Research UK. All rights reserved 0007-0920/17 
The relevance of optimal timing of surgery and adjuvant treatment is widely described in the literature, showing that delays in surgery (Shin et al, 2013; Bleicher et al, 2016) and adjuvant treatments (Trufelli et al, 2015) are likely to decrease treatment efficacy. In terms of the optimal timing of radiation therapy (RT) following breast-conserving surgery (BCS) much controversy exists. The general perception is that increasing time intervals between BCS and RT are correlated with adverse survival outcomes (Mikeljevic et al, 2004; Hershman et al, 2006; Chen et al, 2008; Tsoutsou et al, 2009; Gupta et al, 2016). Though, various other studies have shown that time interval between surgery and RT is unrelated to locoregional recurrence-free survival (LRRFS) (Froud et al, 2000; Livi et al, 2009; Barbieri et al, 2011; Downing et al, 2011; Corradini et al, 2014; Vujovic et al, 2015). Others reported that larger time intervals ( $>53$ days) were significantly associated with increased disease-free (DFS) and distant metastasis-free survival (DMFS; Jobsen et al, 2006, 2013). However, these study populations are very heterogeneous, making it impossible to draw firm conclusions. Despite this, most indicators aiming to describe quality of care are process indicators regarding timing of therapy. In the Netherlands, the NABON (National Breast cancer Working group) Breast Cancer Audit (NBCA) defined the indicator on timing of RT as within 5 weeks of BCS, for patients not receiving chemotherapy between BCS and RT (Dutch Institute for Clinical Auditing (DICA), 2015). In 2013, the annual report of the NBCA demonstrated that this criterion was fulfilled for only $45 \%$ of the patients. However, 75\% was treated with RT within 6 weeks $(42$ days) of BCS (Dutch Institute for Clinical Auditing (DICA), 2013).

No nationwide population-based studies have been performed to investigate the relation between timing of RT following BCS and 10-year DFS, LRRFS, DMFS and overall survival (OS) in early breast cancer in the Netherlands. The aim of this study was to determine the effect of time intervals between BCS and RT on 10year DFS, LRRFS, DMFS and OS in Dutch breast cancer patients. To achieve this, we investigated two populations: one in which patients receiving chemotherapy before RT were excluded, in order to determine the relevance of the NBCA indicator, and one in which patients receiving chemotherapy before and after RT were compared.

\section{MATERIALS AND METHODS}

Design. In this historic cohort study, patient-, tumour- and treatment-related characteristics were obtained from the population-based Netherlands Cancer Registry. Tumour characteristics were coded according to the International Classification of Diseases for Oncology (ICD-O, third edition) (Fritz et al, 2000) and the tumour, node and metastasis (TNM) classification system of the International Union Against Cancer, sixth edition (Sobin and Wittekind, 2002). Data on vital status and date of death were derived from the Municipal Personal Records Database. Data on all recurrences that occurred within 10 years after diagnosis were gathered retrospectively from patient files and were complete for all patients included in this study. This study has been approved by the privacy committee of The Netherlands Cancer Registry.

Patients. All women diagnosed with primary invasive stage I-IIIA breast cancer in 2003, treated with BCS with RT, of whom the start date of RT was known and follow-up was complete, were included. Patients who had Paget's disease, macroscopic residual tumour left after the operation, treated in an unknown hospital, had extreme time intervals exceeding 365 days, or were treated with RT before BCS were excluded. First, we investigated our research question in all early breast cancer patients, where we excluded patients treated with chemotherapy between BCS and RT (Population 1). Since adjuvant systemic therapy (endocrine therapy and/or chemotherapy, AST) has a direct effect on survival (Early Breast Cancer Trialists' Collaborative Group (EBCTCG), 2005), we stratified these analyses for use of AST. Adjuvant endocrine therapy could have been started before, concurrently with, or following RT. Second, the same research question was studied in patients treated with chemotherapy before RT (BCS-chemotherapy-RT) and we compared the results with patients receiving chemotherapy after RT (BCS-RT-chemotherapy) (Population 2). The patients treated with chemotherapy after RT are consequently part of both populations (Figure 1).

Definitions and outcomes. The time between BCS and RT was defined as the number of days from the date of most recent surgery until the start of RT. Most recent surgery was defined as BCS of the primary tumour, or as the moment of axillary lymph node dissection, if this was performed following BCS. In case of reexcision, the date of last BCS was used. We categorised patients into three interval groups based on the NBCA indicator: $<42$ days (most patients receive RT within 42 days), 42-55 days and $>55$ days. For BCS-chemotherapy-RT, the median time interval was larger, and therefore the following interval groups were created, based on the distribution of BCS-RT interval among patients: $<112$ days, 112-140 days and >140 days. Local and distant recurrences were defined according to existing consensus-based definitions for recurrence classification (Moossdorff et al, 2014; Gourgou-Bourgade et al, 2015). The primary outcome of this study was 10-year DFS (cumulative probability of being free from any recurrence, within 10 years after diagnosis). Secondary outcomes were 10-year LRRFS, 10-year DMFS (cumulative probability of being free from locoregional recurrences or distant metastases, respectively, within 10 years after diagnosis) and 10-year OS (death due to all causes).

Statistical analysis. Potential confounding variables were compared among the interval groups using the $\chi^{2}$, Fisher's exact or Kruskal-Wallis test. Small amounts of missing data were present for several prognostic variables. Since these missing variables are most likely limited to an earlier year of diagnosis (over recent years the registration of data has become more strict), and were not expected to be related to any unobserved data, we considered the missing data as missing at random. To account for missing data, multiple imputation was performed using the mi impute chained equation command in STATA (Release 14, StataCorp LP, College Station, TX, USA). The imputation, based on event indicators and estimated Nelson-Aalen cumulative hazards (White and Royston, 2009), was performed 20 times and Rubin's rule was used to combine the estimates and standard errors (White et al, 2011).

We used the Kaplan-Meier method and the log-rank test to compare crude 10-year DFS, LRRFS and DMFS among the interval groups. To correct for confounding, we used multivariable Cox regression to estimate hazard ratios (HRs) with 95\% confidence intervals (CIs) for 10-year DFS, LRRFS and DMFS. For Population 1 , all analyses were stratified for use of AST (chemotherapy and/or endocrine therapy $=$ yes, none $=$ no). For Population 2, analyses were performed separately for BCS-RT-chemotherapy and BCSchemotherapy-RT. Potential confounding variables (variables that are related to the timing of RT as well as the survival outcomes) varying among interval groups were included in the multivariable models $(P<0.1)$. A $P$-value $<0.05$ was considered to be statistically significant. All analyses were executed in STATA version 14.1.

\section{RESULTS}

Population 1 consisted of 2759 patients (Figure 1). None of the included patients received primary systemic therapy. The median number of days between BCS and RT was 45 (IQR 37-54; Figure 2). The distribution of time interval for patients treated with 


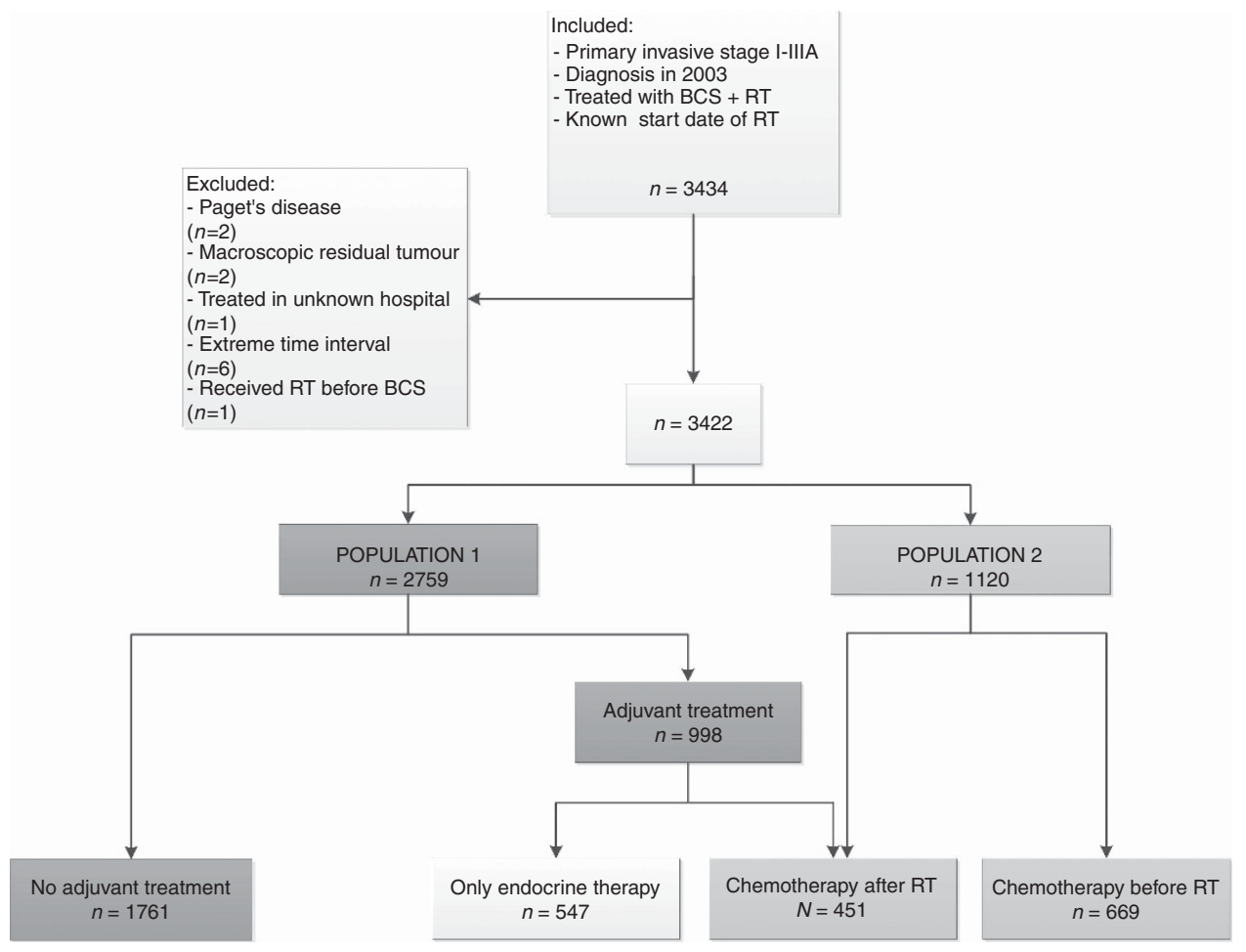

Figure 1. Flowchart of patient selection. The orange parts on the left indicate the stratified groups in Population 1. The green parts on the right indicate the stratified groups in Population 2. Patients receiving chemotherapy after RT (Population 2) are also part of the adjuvant systemic therapy group of Population 1. BCS, breast-conserving surgery, RT, radiation therapy. A full colour version of this figure is available at the British journal of cancer journal online.

and without AST is shown in Supplementary Figure 1. Patient, treatment, and tumour-related characteristics per interval group are summarised in Table 1. Longer time intervals were most common in older patients, patients not treated with AST and patients who were referred to a RT department in another hospital. Patients treated with AST showed less favourable tumour characteristics compared to patients not treated with AST (Supplementary Table 1).

Population 2 consisted of 1120 patients (Figure 1). The median number of days between BCS and RT was 43 (IQR 35-51) for BCSRT-chemotherapy, and 124 (IQR 111-144) for BCS-chemotherapy-RT (Supplementary Figure 2). Patient, treatment and tumourrelated characteristics per interval group and timing of chemotherapy are summarised in Table 2.

Population 1: timing of RT and 10-year survival, stratified for use of AST. In the $<42$ days group, 178 of 1079 patients (16.5\%) were diagnosed with a recurrence within 10 years of diagnosis. In the 42-55 days group, 141 of $1074(13.1 \%)$ patients experienced a recurrence, and in the $>55$ days group, 73 of 606 (12.1\%) patients experienced a recurrence. The distribution of distant metastases varied significantly among interval groups, but the distribution of locoregional recurrences did not (Supplementary Figure 3). The distribution of recurrences for patients treated with and without AST is shown in Supplementary Figure 4. Patients treated with adjuvant systemic therapy showed a higher number of distant metastases in the $<42$ days group, compared to the other groups.

Kaplan-Meier curves of crude 10-year DFS, LRRFS and DMFS for the entire cohort are shown in Supplementary Figure 5. A significant difference among the interval groups was observed for 10-year DFS and DMFS, with the highest DFS and DMFS seen for $>55$ days, and the lowest for $<42$ days $(P<0.05)$. Time interval was not significantly associated with 10-year LRRFS. After stratification, 10year DFS was significantly better for longer time intervals in patients treated with AST (Supplementary Figure 6).
In the multivariable analysis, 10-year DFS was significantly better for the time interval of $>55$ days (HR 0.71 (95\% CI: 0.56-0.90)) compared to $<42$ days. The HR for $42-55$ days was 0.78 (95\% CI: 0.64-0.95), compared to $<42$ days. After stratification, significantly higher DFS was observed for patients treated with AST (HR 0.63 (95\% CI: 0.41-0.95) for a time interval of >55 days and 0.71 (95\% CI: 0.52-0.98) for 42-55 days compared to $<42$ days). No differences in DFS among interval groups existed for patients not treated with AST (Table 3).

Ten-year LRRFS was not significantly different among interval groups, which persisted after stratification for use of AST (Table 3).

Ten-year DMFS was significantly better for a time interval of $>55$ days (HR 0.64 (95\% CI: 0.45-0.92)) compared to $<42$ days. No significant difference existed between $42-55$ and $<42$ days. After stratification, we revealed that in patients treated with AST, $>55$ (HR 0.59 (95\% CI: 0.36-0.96)) and 42-55 days (HR 0.69 (95\% CI: $0.47-1.00)$ ) were significantly related to better 10 -year DMFS than $<42$ days. No significant differences were found for patients not treated with AST (Table 3).

Ten-year OS was not significantly different among interval groups in the entire cohort. However, after stratification, significantly lower OS was observed in patients not treated with AST for $>55$ days (HR 1.51 (95\% CI: 1.17-2.11)) and 42-55 days (HR 1.57 (95\% CI: $1.17-1.96)$ ) compared to $<42$ days between surgery and RT. In patients treated with AST, no significant differences were found (Table 3).

Population 2: timing of RT and 10-year survival, stratified for timing of chemotherapy. For BCS-RT-chemotherapy, 47 of 201 patients $(23.4 \%)$ in the $<42$ days group were diagnosed with a recurrence within 10 years of diagnosis. In the $42-55$ days group, 30 of $176(17.1 \%)$ patients experienced a recurrence, and in the $>55$ days group, 8 of $70(10.8 \%)$ patients experienced a recurrence. For BCS-chemotherapy-RT, 31 of 181 patients $(17.1 \%)$ in the $<112$ days group were diagnosed with a recurrence 


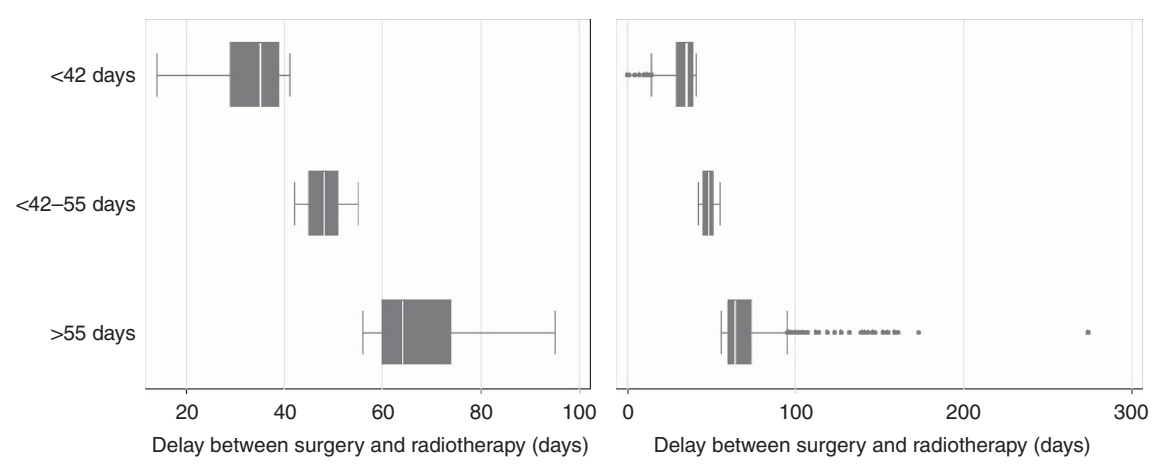

Figure 2. Population 1: Distribution of time intervals between BCS and RT. The left panel shows the distribution without outliers. The right panel shows the distribution including outliers.

within 10 years of diagnosis. In the 112-140 days group, 50 of 301 (16.6\%) patients experienced a recurrence, and in the $>140$ days group, 49 of 187 (26.2\%) patients experienced a recurrence. The distribution of any recurrence and distant metastases varied significantly among interval groups-irrespective of timing of chemotherapy-while the distribution of locoregional recurrences did not vary significantly (Supplementary Figure 7).

Kaplan-Meier curves show that for BCS-RT-chemotherapy, time interval is not related to 10-year DFS, LRRFS and DMFS. However, for 10-year DMFS, a clear trend towards significance is observed in favour of longer time intervals $(P=0.052)$. For BCSchemotherapy-RT, shorter time intervals are related to higher 10year DFS and DMFS $(P<0.05)$, while time interval was not significantly associated with 10-year LRRFS (Supplementary Figure 8).

After correction for confounding, time interval was not significantly associated with 10-year DFS, LRRFS and OS for BCS-RT-chemotherapy, while 10-year DMFS was significantly higher for $>55$ days (HR 0.44 (95\% CI: 0.19-0.99)) compared to $<42$ days. For BCS-chemotherapy-RT, time interval was not significantly associated with any outcome (Table 4).

\section{DISCUSSION}

This study shows that in patients not treated with AST after RT, time interval between BCS and RT is not significantly related to 10year DFS, LRRFS and DMFS, but that increasing time intervals lead to lower 10-year OS. In patients treated with AST after RT, higher 10-year DFS and DMFS at increasing time intervals were seen. In patients treated with chemotherapy (Population 2), we found significantly improved 10-year DMFS for $>55$ days compared to $<42$ days in the BCS-RT-chemotherapy group, while time interval is not significantly associated with any outcome in the BCS-chemotherapy-RT group.

This may imply that patients who are treated with adjuvant chemotherapy may possibly benefit from a slightly longer time interval when receiving chemotherapy after RT, while patients not treated with AST may have better OS when start RT $<42$ days after BCS. When receiving chemotherapy between BCS and RT (BCS-chemotherapy-RT), timing is not significantly related to all investigated survival outcomes. In general, patients not receiving AST present with a good prognosis, or with a decreased life expectancy due to age or comorbidity. In these patients there is evidence that RT does not affect DMFS (Hughes et al, 2013; Kunkler et al, 2015). This may explain why RT does not depend on timing in these patients. What may be remarkable for some readers is that the majority of the patients in this population (2003) was not treated with AST. However, this is in line with the Dutch nationwide evidence-based guidelines valid at that time (Rutgers et al, 2002).In addition, according to the current Dutch guidelines, these patients would neither be treated with AST nowadays. Importantly, AST in general is recommended when the absolute risk on 10-year mortality is equal to or more than $15 \%$, and for most patients the risk on mortality will be reduced with $4-5 \%$. The guideline states that the survival benefit of chemotherapy is limited in older patients and patients with early, ER positive breast cancer. Since our study population primarily consists of patients with early, ER positive disease, and the share of older patients is substantial, chemotherapy is not expected to be administered to a large proportion of patients. Endocrine therapy is primarily recommended for patients with positive lymph nodes and ER positive breast cancer or patients without positive nodes and unfavourable tumour characteristics. Approximately 20\% of our population presented with positive lymph nodes, and around $30 \%$ of the patients received endocrine therapy (only or in combination with chemotherapy), which is in line with the abovementioned guidelines. (Nationaal Borstkanker Overleg Nederland (NABON), 2012).

Our findings that longer time intervals may lead to better DFS and DMFS in patients treated with AST are more difficult to interpret. Since not all hospitals in The Netherlands have a RT department, BCS-RT time intervals may increase for patients who have to be referred to a RT department of another hospital. However, with the oncological structure as set up in The Netherlands this is not likely to be the case. Moreover, since this factor is not related to the outcome (supporting the beforementioned), but is directly related to the time interval, it is not a confounding variable and should not explain the observed results. One possible argument may be that patients with worse prognosis receive RT earlier and consequently have a shorter time interval between surgery and RT (so in a way a reversed causal effect). In this study, patients under 40 years were more often treated with RT within 42 days following surgery. In addition, patients in the $<42$ days group had slightly larger tumours compared to the other groups, and more often had a higher grade. Another suggested mechanism deals with the release of various humoral factors after surgery leading (amongst others) to angiogenesis which contributes to the process of wound healing. This is hypothesised to contribute to growth of previously dormant metastatic cells (Baum et al, 2005). It should be stressed also that normally RT deteriorates the ability of cancer cells to create angiogenesis and, hereby, deteriorates the ability to metastasise. Starting RT too early after surgery may, due to the release of various humoral factors, lead to repair of this type of radiation-induced damage and may therefore not lead to deterioration of angiogenesis. The latter may also explain why we find an effect of timing on DMFS, but not on LRRFS. However, this hypothesis should be confirmed in further studies. Since the chance of metastases is related to several prognostic characteristics of the tumour-that are presumably worse in patients treated with chemotherapy-the effect of timing of RT 
Table 1. Population 1, baseline characteristics according to interval category $(n=2759)$

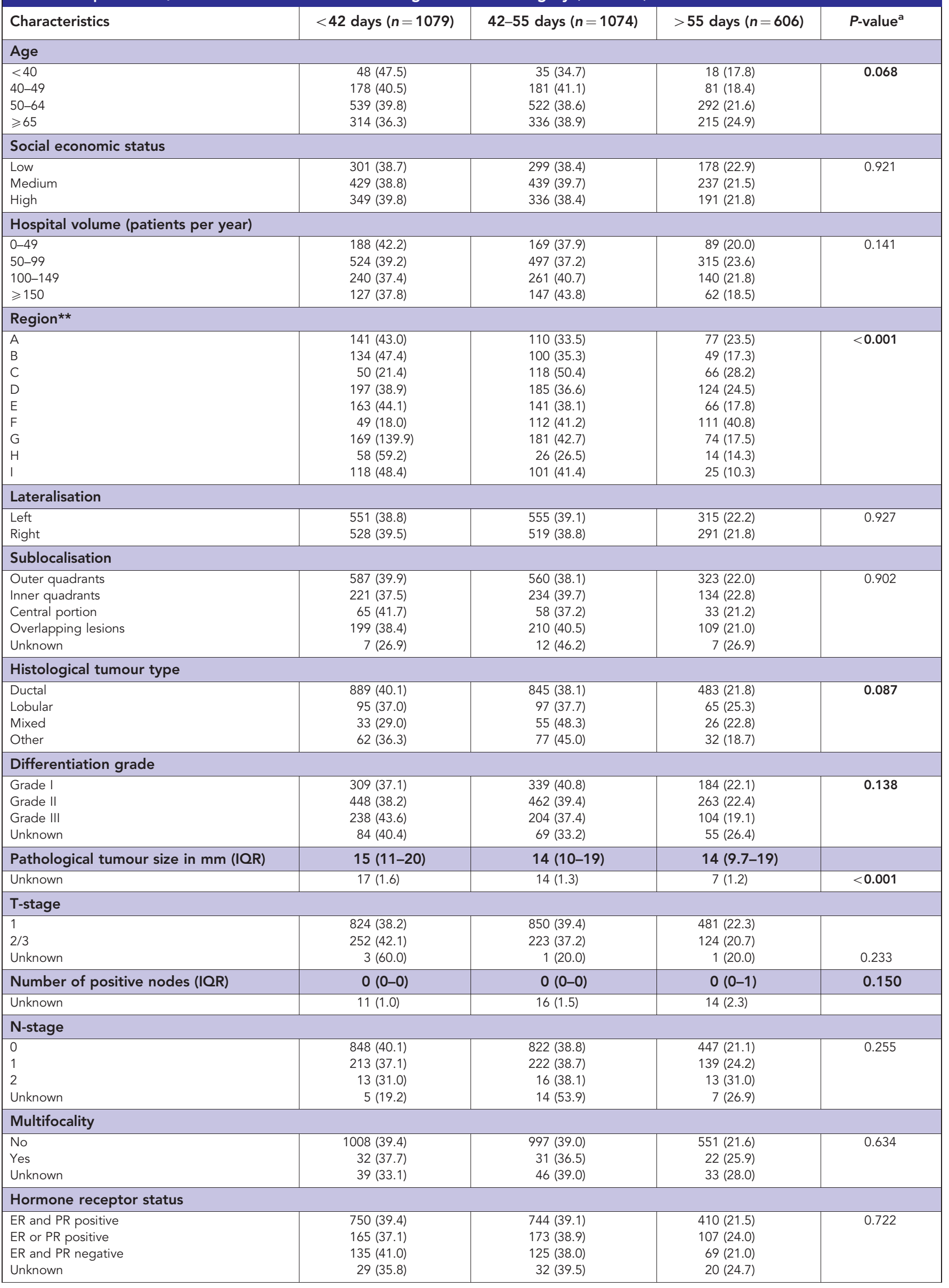




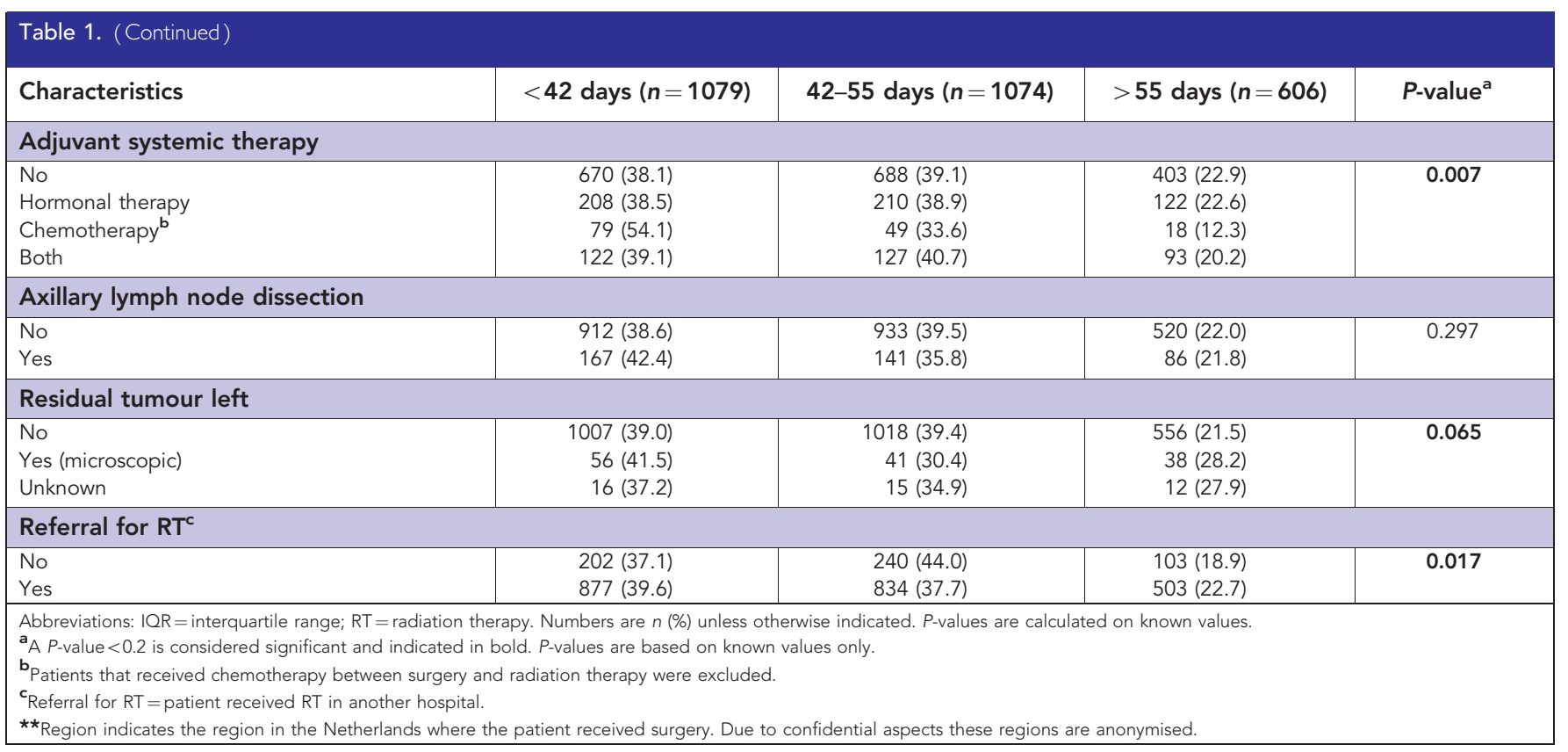

following surgery may be more pronounced in patients receiving chemotherapy after RT. However, this outcome definitely needs further research, also given the complexity of the interplay between RT and AST (Punglia et al, 2007). Our study agrees with other studies that timing of RT is not significantly related to DFS in patients not treated with AST (Vujovic et al, 2015; Caponio et al, 2016) However, two other studies showed the opposite (Jobsen et al, 2006, 2013). Possible explanations for this discrepancy are the use of different intervals between treatments, different study designs (population-based $v s$ single-centre-based), and different study populations. Our results confirm previous studies showing no relationship between timing of RT and LRRFS (Froud et al, 2000; Jobsen et al, 2006, 2013; Vujovic et al, 2015) Furthermore, another study found that a time interval over seven months between BCS and RT did not affect DFS and DMFS in patients receiving chemotherapy before RT, thereby confirming our results (Koh et al, 2016). Finally, we found lower OS for patients not treated with AST with increasing time intervals. This may be explained by the larger share of older patients in the larger interval groups.

Strengths and limitations of the study. To our knowledge, this is the first study that investigated the relevance of the NBCA indicator in the Netherlands, and moreover, the overall effect of timing of RT on survival. Besides, we compared the effect of timing in patients receiving chemotherapy before and after RT. These results give a more complete picture of the effect of time interval between BCS and RT. The study's population-based setting increases the generalisability of the results.

A limitation of this study is lacking data on postoperative complications, delaying RT, lymphovascular invasion, mitotic activity index and Her2 receptor status. Any differences in these factors or other unmeasured confounders among interval groups may have introduced confounding by severity. For the Her2 status, it must be noted that it was not routinely determined in 2003, with anti-Her2 therapies being introduced in Dutch clinical practice only in 2005. For patients receiving chemotherapy before RT (BCSchemotherapy-RT), we lacked data on start of the last cycle of chemotherapy. Therefore, we could not take the time between last cycle of chemotherapy and start of RT into account. Since endocrine therapy is quite often started concurrently with RT, we do not expect that the use of endocrine therapy caused a delay in starting RT. Another limitation is that we could not include 1482 patients (35\% of total) due to an unknown start date of RT. As this number is substantial, we thoroughly investigated this population. Fortunately, these patients had similar baseline characteristics and survival outcomes as the population under study. In addition, since start dates of RT are cumbersome to retrieve retrospectively from RT reports, we do not expect that patients with a missing start date are a selective group. Therefore, we do not expect this to have influenced our results other than a lower number of included patients. Finally, as this study is observational, we cannot exclude additional confounding by severity and residual confounding.

Implications for clinical practice. Our most important message is that it is not necessary to start RT as soon as possible after BCS, as it does not increase survival rates. Patients should be informed about this, preventing them from worrying about tumour growth and worse outcomes in case of a longer time interval between BCS and RT. In addition, the relevance of the NBCA indicator may be questioned. These results may not only be useful for the Dutch clinical practice, but it may also be of importance for other countries. There is a lot of controversy regarding timing of RT. Population-based studies, such as this study, may contribute to a better understanding of the effect of timing on survival outcomes and may refute the common understanding that RT should start as soon as possible after RT. Clearly, we cannot conclude that delays can be extended infinitely: other studies suggested that delays exceeding 20 weeks (Mikeljevic et al, 2004; Olivotto et al, 2009) lead to reduced survival rates. In addition, from a psychological point of view a short time interval can be more convenient.

The question raises whether it would be beneficial to start chemotherapy before RT (BCS-chemotherapy-RT). Additional analyses on our data revealed that the sequence of chemotherapy and RT does not affect 10-year survival outcomes (data not shown). This is confirmed by a recently published randomised trial (Karlsson et al, 2016). However, since the optimum timing of RT may largely be related to several prognostic factors (Livi et al, 2009), further research needs to define a precise range in delay that has the most favourable effect on survival in predefined subgroups.

The fact that the majority of our population was not treated with AST (which is according to our guidelines),may limit the 
Table 2. Population 2 , baseline characteristics according to timing of chemotherapy $(n=1120)$

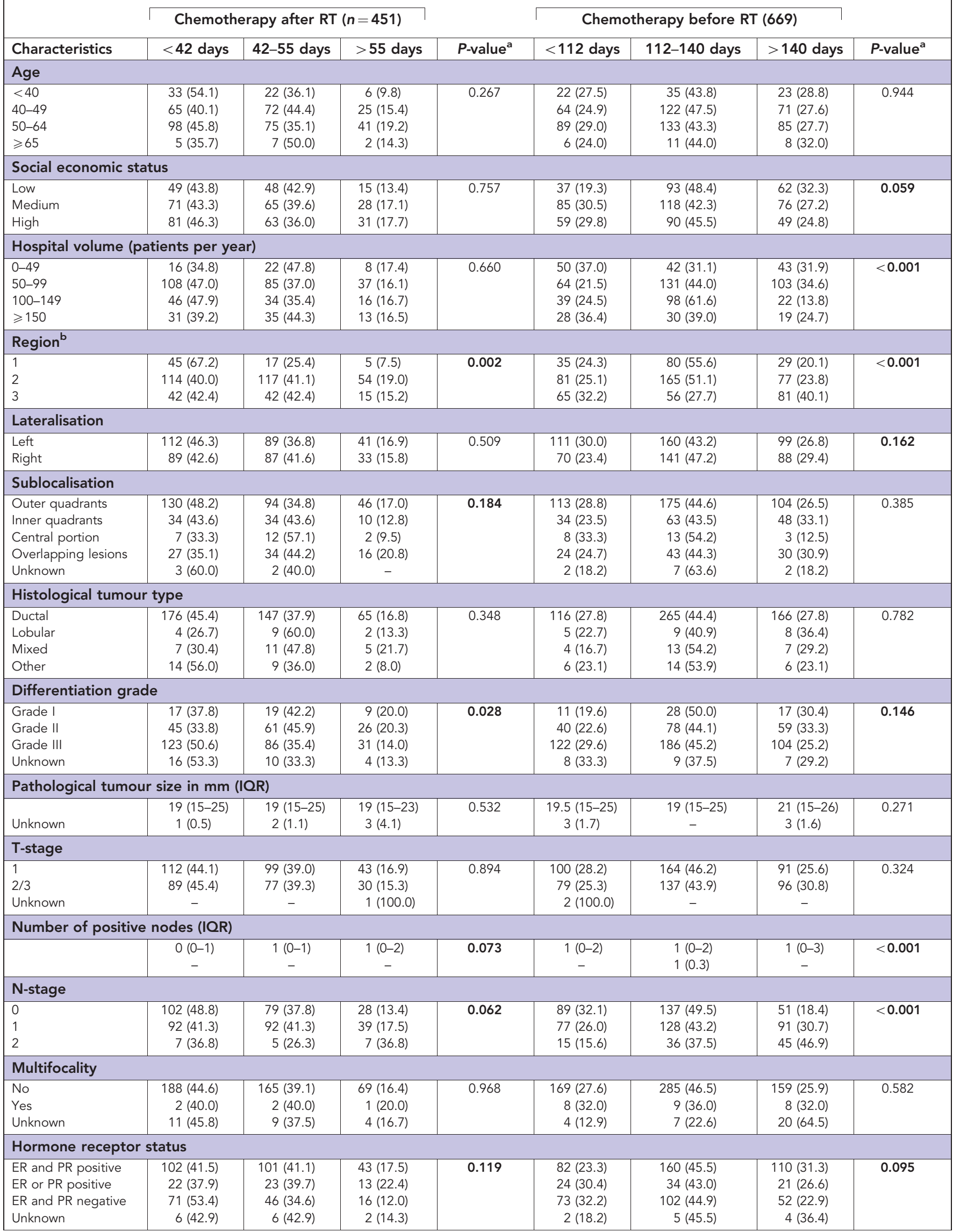




\section{Table 2. (Continued)}

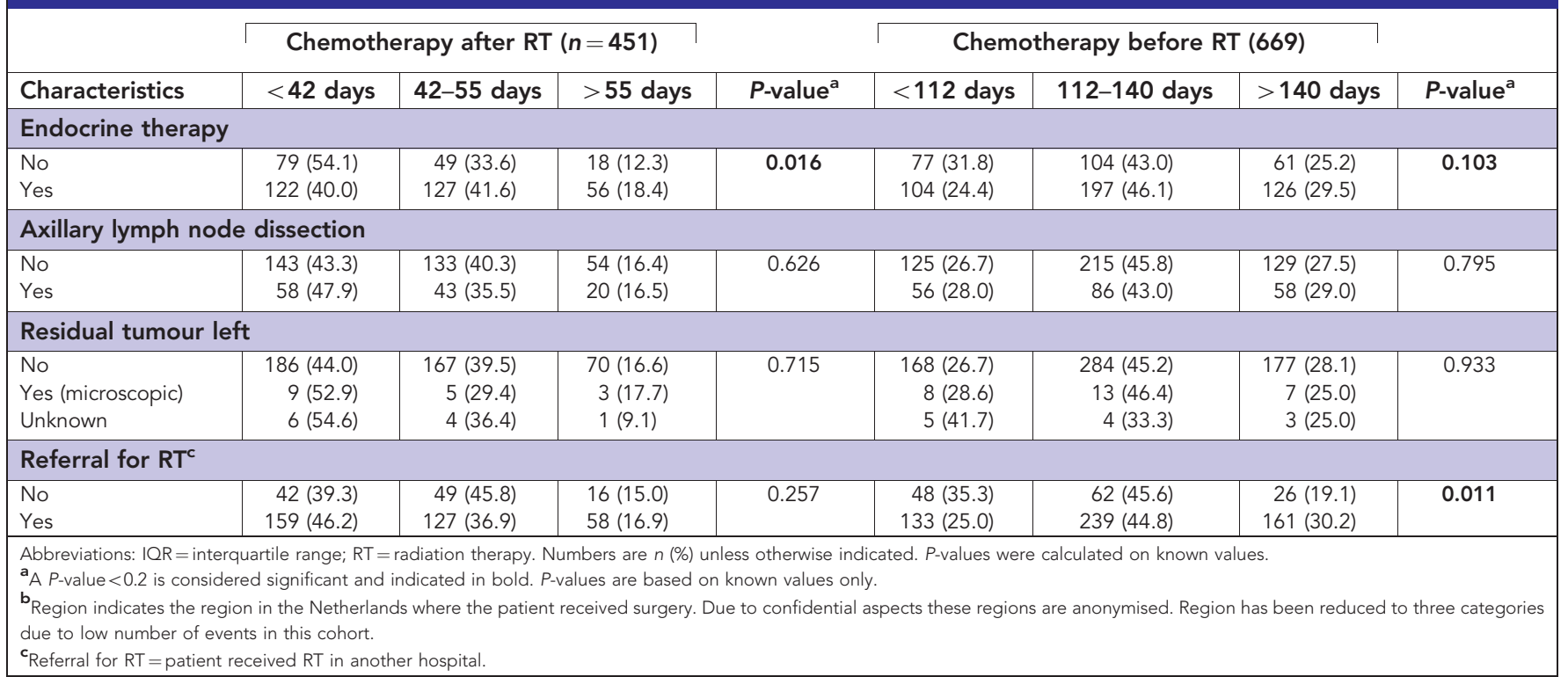

Table 3. Population 1, 10-year disease-free, locoregional recurrence-free, distant metastasis-free and overall survival for different time intervals between surgery and radiation therapy in breast cancer patients, stratified for use of adjuvant systemic therapy

\begin{tabular}{|c|c|c|c|c|c|c|}
\hline & \multicolumn{2}{|c|}{ Entire cohort $(n=2759)$} & \multicolumn{2}{|c|}{ No adjuvant treatment $(n=1761)$} & \multicolumn{2}{|c|}{ Adjuvant treatment $(n=998)$} \\
\hline & Crude & Multivariable $^{a}$ & Crude & Multivariable $^{\mathrm{b}}$ & Crude & Multivariable $^{c}$ \\
\hline Time interval & HR $(95 \% \mathrm{Cl})$ & $\mathrm{HR}(95 \% \mathrm{Cl})$ & $\mathrm{HR}(95 \% \mathrm{Cl})$ & $\mathrm{HR}(95 \% \mathrm{Cl})$ & $\mathrm{HR}(95 \% \mathrm{Cl})$ & $\mathrm{HR}(95 \% \mathrm{Cl})$ \\
\hline $\begin{array}{l}<42 \text { days } \\
42-55 \text { days } \\
>55 \text { days }\end{array}$ & $\begin{array}{c}1 \\
0.77(0.64-0.93) \\
P=0.006 \\
0.72(0.57-0.90) \\
P=0.004\end{array}$ & $\begin{array}{c}1 \\
0.78(0.64-0.95) \\
P=0.011 \\
0.71(0.56-0.90) \\
P=0.005\end{array}$ & $\begin{array}{c}1 \\
0.79(0.63-1.01) \\
P=0.055 \\
0.75(0.56-0.99) \\
P=\mathbf{0 . 0 4 4}\end{array}$ & $\begin{array}{c}1 \\
0.81(0.64-1.03) \\
P=0.086 \\
0.76(0.57-1.02) \\
P=0.064\end{array}$ & $\begin{array}{c}1 \\
0.73(0.53-0.99) \\
P=0.042 \\
0.66(0.45-0.98) \\
P=0.041\end{array}$ & $\begin{array}{c}1 \\
0.71(0.52-0.98) \\
P=0.035 \\
0.63(0.41-0.95) \\
P=\mathbf{0 . 0 2 9}\end{array}$ \\
\hline \multicolumn{7}{|c|}{ Secondary outcome: 10 -year LRRFS } \\
\hline $\begin{array}{l}<42 \text { days } \\
42-55 \text { days } \\
>55 \text { days }\end{array}$ & $\begin{array}{c}1 \\
0.69(0.48-0.97) \\
P=0.035 \\
0.80(0.54-1.20) \\
P=0.282\end{array}$ & $\begin{array}{c}1 \\
0.72(0.50-1.03) \\
P=0.072 \\
0.90(0.59-1.37) \\
P=0.620\end{array}$ & $\begin{array}{c}1 \\
0.74(0.49-1.13) \\
P=0.163 \\
0.88(0.55-1.41) \\
P=0.605\end{array}$ & $\begin{array}{c}1 \\
0.77(0.50-1.17) \\
P=0.221 \\
0.97(0.60-1.57) \\
P=0.904\end{array}$ & $\begin{array}{c}1 \\
0.54(0.27-1.05) \\
P=0.069 \\
0.63(0.28-1.40) \\
P=0.255\end{array}$ & $\begin{array}{c}1 \\
0.55(0.28-1.10) \\
P=0.092 \\
0.68(0.29-1.57) \\
P=0.363\end{array}$ \\
\hline \multicolumn{7}{|c|}{ Secondary outcome: 10 -year OS } \\
\hline $\begin{array}{l}<42 \text { days } \\
42-55 \text { days } \\
>55 \text { days }\end{array}$ & $\begin{array}{c}1 \\
1.17(0.97-1.41) \\
P=0.110 \\
1.24(1.00-1.54) \\
P=0.051\end{array}$ & $\begin{array}{c}1 \\
1.20(0.98-1.45) \\
P=0.071 \\
1.21(0.96-1.52) \\
P=0.107\end{array}$ & $\begin{array}{c}1 \\
1.42(1.10-1.82) \\
P=0.007 \\
1.44(1.08-1.91) \\
P=0.013\end{array}$ & $\begin{array}{c}1 \\
1.51(1.17-1.96) \\
P=0.002 \\
1.57(1.17-2.11) \\
P=0.003\end{array}$ & $\begin{array}{c}1 \\
0.91(0.68-1.21) \\
P=0.504 \\
1.05(0.75-1.47) \\
P=0.777\end{array}$ & $\begin{array}{c}1 \\
0.83(0.61-1.12) \\
P=0.219 \\
0.87(0.61-1.25) \\
P=0.466\end{array}$ \\
\hline $\begin{array}{l}\text { Abbreviations: } \mathrm{Cl} \\
\text { survival. } P \text {-values } \\
{ }^{\mathrm{a}} \text { Corrected for ag } \\
\text { operation, adjuvar } \\
{ }^{\mathrm{b}} \text { Corrected for ho } \\
{ }^{\mathrm{c}} \text { Corrected for ag }\end{array}$ & $\begin{array}{l}\text { c therapy. } \\
\text { ume, region, histolo } \\
\text { differentiation grad }\end{array}$ & $\begin{array}{l}\text { al tumour type, diffe } \\
\text { nour type, exact tum } \\
\text { number of positive }\end{array}$ & $\begin{array}{l}\text { nt metastasis-free su } \\
5 \text { ). } \\
\text { tion grade, exact tun } \\
(\mathrm{mm}) \text {, exact numb }\end{array}$ & $\begin{array}{l}\mathrm{HR}=\text { hazards ratio; } \mathrm{LP} \\
\text { ze }(\mathrm{mm}) \text {, exact numbe } \\
\text { ositive lymph nodes. }\end{array}$ & $\begin{array}{l}\text { locoregional recurrer } \\
\text { ositive lymph nodes, }\end{array}$ & $\begin{array}{l}\text { ee survival; OS= over } \\
\text { ual tumour left after t }\end{array}$ \\
\hline
\end{tabular}

generalisability of the results to other countries, where the indication for administering AST may differ.

Importantly, developments in the treatment of breast cancer include the increasing use of primary systemic therapy. It should be further investigated whether these results hold true when systemic therapy is not given after, but before surgery of the primary tumour. It would also be of interest to investigate if the results hold true in subgroups based on molecular subtype. 
Table 4. Population 2, 10-year disease-free, locoregional recurrence-free, distant metastasis-free and overall survival for different time intervals between surgery and radiation therapy in breast cancer patients, stratified for timing of chemotherapy

\begin{tabular}{|c|c|c|c|c|c|}
\hline \multicolumn{3}{|c|}{ BCS-RT-chemotherapy $(n=451)$} & \multicolumn{3}{|c|}{ BCS-chemotherapy-RT $(n=667)$} \\
\hline & Crude & Multivariable $^{a}$ & & Crude & Multivariable \\
\hline Time interval & $\mathrm{HR}(95 \% \mathrm{CI})$ & $\mathrm{HR}(95 \% \mathrm{Cl})$ & Time interval & HR $(95 \% \mathrm{Cl})$ & $\mathrm{HR}(95 \% \mathrm{Cl})$ \\
\hline \multicolumn{6}{|c|}{ Primary outcome: 10-year DFS } \\
\hline $\begin{array}{l}<42 \text { days } \\
42-55 \text { days } \\
>55 \text { days }\end{array}$ & $\begin{array}{c}1 \\
0.70(0.45-1.11) \\
P=0.133 \\
0.45(0.21-0.95) \\
P=0.036\end{array}$ & $\begin{array}{c}1 \\
0.77(0.48-1.25) \\
P=0.291 \\
0.48(0.22-1.03) \\
P=0.061\end{array}$ & $\begin{array}{l}<112 \text { days } \\
112-140 \text { days } \\
>140 \text { days }\end{array}$ & $\begin{array}{c}1 \\
0.95(0.61-1.49) \\
P=0.824 \\
1.60(1.02-2.51) \\
P=0.040\end{array}$ & $\begin{array}{c}1 \\
0.90(0.57-1.43) \\
P=0.654 \\
1.23(0.76-2.00) \\
P=0.389\end{array}$ \\
\hline \multicolumn{6}{|c|}{ Secondary outcome: 10-year LRRFS } \\
\hline $\begin{array}{l}<42 \text { days } \\
42-55 \text { days } \\
>55 \text { days }\end{array}$ & $\begin{array}{c}1 \\
0.74(0.30-1.80) \\
P=0.505 \\
0.88(0.28-2.72) \\
P=0.820\end{array}$ & $\begin{array}{c}1 \\
0.96(0.38-2.42) \\
P=0.939 \\
1.16(0.36-3.79) \\
P=0.804\end{array}$ & $\begin{array}{c}<112 \text { days } \\
112-140 \text { days } \\
>140 \text { days }\end{array}$ & $\begin{array}{c}1 \\
1.05(0.53-2.08) \\
P=0.882 \\
1.19(0.57-2.50) \\
P=0.646\end{array}$ & $\begin{array}{c}1 \\
1.13(0.56-2.30) \\
P=0.736 \\
1.02(0.46-2.26) \\
P=0.967\end{array}$ \\
\hline \multicolumn{6}{|c|}{ Secondary outcome: 10-year DMFS } \\
\hline $\begin{array}{l}<42 \text { days } \\
42-55 \text { days } \\
>55 \text { days }\end{array}$ & $\begin{array}{c}1 \\
0.68(0.42-1.11) \\
P=0.122 \\
0.44(0.20-0.98) \\
P=0.044\end{array}$ & $\begin{array}{c}1 \\
0.72(0.43-1.20) \\
P=0.212 \\
0.44(0.19-0.99) \\
P=\mathbf{0 . 0 4 8}\end{array}$ & $\begin{array}{l}<112 \text { days } \\
112-140 \text { days } \\
>140 \text { days }\end{array}$ & $\begin{array}{c}1 \\
0.89(0.54-1.47) \\
P=0.652 \\
1.69(1.03-2.77) \\
P=\mathbf{0 . 0 3 8}\end{array}$ & $\begin{array}{c}1 \\
0.83(0.49-1.39) \\
P=0.482 \\
1.25(0.73-2.12) \\
P=0.415\end{array}$ \\
\hline \multicolumn{6}{|c|}{ Secondary outcome: 10-year OS } \\
\hline $\begin{array}{l}<42 \text { days } \\
42-55 \text { days } \\
>55 \text { days }\end{array}$ & $\begin{array}{c}1 \\
0.80(0.51-1.29) \\
P=0.364 \\
0.78(0.41-1.48) \\
P=0.449\end{array}$ & $\begin{array}{c}1 \\
0.92(0.56-1.50) \\
P=0.726 \\
0.86(0.44-1.69) \\
P=0.669\end{array}$ & $\begin{array}{c}<112 \text { days } \\
112-140 \text { days } \\
>140 \text { days }\end{array}$ & $\begin{array}{c}1 \\
1.09(0.69-1.71) \\
P=0.717 \\
1.68(1.06-2.67) \\
P=0.027\end{array}$ & $\begin{array}{c}1 \\
1.02(0.64-1.63) \\
P=0.935 \\
1.36(0.83-2.22) \\
P=0.224\end{array}$ \\
\hline \multicolumn{6}{|c|}{$\begin{array}{l}\text { Abbreviations: } \mathrm{Cl}=\text { confidence interval; DFS }=\text { disease-free survival; DMFS }=\text { distant metastasis-free survival; HR }=\text { hazards ratio; LRRFS }=\text { locoregional recurrence-free survival; OS }=\text { overall } \\
\text { survival. } P \text {-values depicted in bold are considered as statistically significant }(P<0.05) \text {. } \\
{ }^{\text {a } C o r r e c t e d ~ f o r ~ r e g i o n, ~ g r a d e, ~ s u b l o c a l i s a t i o n ~ w i t h i n ~ t h e ~ b r e a s t, ~ h o r m o n e ~ r e c e p t o r ~ s t a t u s, ~ a d j u v a n t ~ e n d o c r i n e ~ t h e r a p y . ~} \\
{ }^{b} \text { Corrected for social economic status, hospital volume, region, lateralisation, grade, sublocalisation within the breast, number of positive lymph nodes, hormone receptor status, adjuvant } \\
\text { endocrine therapy. }\end{array}$} \\
\hline
\end{tabular}

\section{CONCLUSIONS}

For patients not treated with AST, timing of RT is not significantly associated with 10-year DFS, LRRFS and DMFS, but larger time intervals are associated with lower OS The latter may be explained by the increased proportion of elderly patients in the larger time interval groups. However, patients treated with AST may benefit from a slightly longer time interval between BCS and RT when receiving chemotherapy after RT (BCS-RT-chemotherapy). For patients receiving chemotherapy before $\mathrm{RT}$, time interval does not influence survival rates. However, the possible interplay between timing of chemotherapy and timing of RT needs further elucidation. In addition, the results should be evaluated further in different subgroups. All in all, we conclude that starting RT as soon as possible after BCS may not be necessary. This suggests that the relevance of the NBCA indicator in The Netherlands, as well as the common position that RT should start as soon as possible after RT can be questioned.

\section{ACKNOWLEDGEMENTS}

We thank The Netherlands Cancer Registry for providing the data, as well as the registration clerks for their effort in gathering the data in the Netherlands Cancer Registry.

\section{CONFLICT OF INTEREST}

The authors declare no conflict of interest.

\section{REFERENCES}

Barbieri V, Sanpaolo P, Genovesi D (2011) Interval between breast-conserving surgery and start of radiation therapy in early-stage breast cancer is not predictive of local recurrence: a single-institution experience. Clin Breast Cancer 11(2): 114-120.

Baum M, Demicheli R, Hrushesky W, Retsky M (2005) Does surgery unfavourably perturb the 'natural history' of early breast cancer by accelerating the appearance of distant metastases? Eur J Cancer 41(4): 508-515.

Bleicher RJ, Ruth K, Sigurdson ER, Beck JR, Ross E, Wong YN, Patel SA, Boraas M, Chang EI, Topham NS, Egleston BL (2016) Time to surgery and breast cancer survival in the United States. JAMA Oncol 2(3): 330-339.

Caponio R, Ciliberti MP, Graziano G, Necchia R, Scognamillo G, Pascali A, Bonaduce S, Milella A, Matichecchia G, Cristofaro C, Di Fatta D, Tamborra P, Lioce M (2016) Waiting time for radiation therapy after breast-conserving surgery in early breast cancer: a retrospective analysis of local relapse and distant metastases in 615 patients. Eur J Med Res 21(1): 32 .

Chen Z, King W, Pearcey R, Kerba M, Mackillop WJ (2008) The relationship between waiting time for radiotherapy and clinical outcomes: a systematic review of the literature. Radiother Oncol 87(1): 3-16.

Corradini S, Niemoeller OM, Niyazi M, Manapov F, Haerting M, Harbeck N, Belka C, Kahlert S (2014) Timing of radiotherapy following breastconserving surgery: outcome of 1393 patients at a single institution. Strahlenther Onkol 190(4): 352-357.

Downing A, Gilthorpe MS, Dodwell D, Lawrence G, Forman D (2011) Waiting times for radiotherapy after breast-conserving surgery and the association with survival: a path analysis. Clin Oncol 23(7): 442-448.

Dutch Institute for Clinical Auditing (DICA) (2013) NBCA Jaarrapportage 2013. DICA: Leiden, Netherlands. Available at: https://www.dica.nl/ jaarrapportage-2013/. 
Dutch Institute for Clinical Auditing (DICA) (2015) Factsheet Indicatoren NABON Breast Cancer Audit. DICA: Leiden, Netherlands. Available at: https://www.dica.nl/media/64/Transparantieportaal\%20Zorg\%202016\%20Indicatorenset\%20NABON\%20Breast\%20Cancer\%20Audit\%20 (NBCA)\%20(verslagjaar\%202015)\%20NBCA\%20mammaregistratie\% 20januari\%202016.pdf.

Early Breast Cancer Trialists' Collaborative Group (EBCTCG) (2005) Effects of chemotherapy and hormonal therapy for early breast cancer on recurrence and 15-year survival: an overview of the randomised trials. Lancet 365(9472): 1687-1717.

Fritz A, Percy C, Jack A, Shanmugarathnam K, Sobin L, Parkin DM, Whelan S (2000) International Classification of Diseases for Oncology, 3rd edition. WHO: Geneva, Switzerland.

Froud PJ, Mates D, Jackson JS, Phillips N, Andersen S, Jackson SM, Bryce CJ, Olivotto IA (2000) Effect of time interval between breast-conserving surgery and radiation therapy on ipsilateral breast recurrence. Int J Radiat Oncol Biol Phys 46(2): 363-372.

Gourgou-Bourgade S, Cameron D, Poortmans P, Asselain B, Azria D, Cardoso F, A'Hern R, Bliss J, Bogaerts J, Bonnefoi H, Brain E, Cardoso MJ, Chibaudel B, Coleman R, Cufer T, Dal Lago L, Dalenc F, De Azambuja E, Debled M, Delaloge S, Filleron T, Gligorov J, Gutowski M, Jacot W, Kirkove C, MacGrogan G, Michiels S, Negreiros I, Offersen BV, Penault Llorca F, Pruneri G, Roche H, Russell NS, Schmitt F, Servent V, Thürlimann B, Untch M, van der Hage JA, van Tienhoven G, Wildiers H, Yarnold J, Bonnetain F, Mathoulin-Pélissier S, Bellera C, Dabakuyo-Yonli TS (2015) Guidelines for time-to-event end point definitions in breast cancer trials: results of the DATECAN initiative (Definition for the Assessment of Time-to-event Endpoints in CANcer trials). Ann of Oncol 26(5): 873-879.

Gupta S, King WD, Korzeniowski M, Wallace DL, Mackillop WJ (2016) The effect of waiting times for postoperative radiotherapy on outcomes for women receiving partial mastectomy for breast cancer: a systematic review and meta-analysis. Clin Oncol 28(12): 739-749.

Hershman DL, Wang X, McBride R, Jacobson JS, Grann VR, Neugut AI (2006) Delay in initiating adjuvant radiotherapy following breast conservation surgery and its impact on survival. Int J Radiat Oncol Biol Phys 65(5): 1353-1360.

Hughes KS, Schnaper LA, Bellon JR, Cirrincione CT, Berry DA, McCormick B, Muss HB, Smith BL, Hudis CA, Winer EP, Wood WC (2013) Lumpectomy plus tamoxifen with or without irradiation in women age 70 years or older with early breast cancer: long-term follow-up of CALGB 9343. J Clin Oncol 31(19): 2382-2387.

Jobsen JJ, van der Palen J, Ong F, Meerwaldt JH (2006) Timing of radiotherapy and survival benefit in breast cancer. Breast Cancer Res Treat 99(3): 289-294.

Jobsen JJ, van der Palen J, Baum M, Brinkhuis M, Struikmans H (2013) Timing of radiotherapy in breast-conserving therapy: a large prospective cohort study of node-negative breast cancer patients without adjuvant systemic therapy. Br J Cancer 108(4): 820-825.

Karlsson P, Cole BF, Price KN, Gelber RD, Coates AS, Goldhirsch A, Castiglione M, Colleoini M, Gruber G, International Breast Cancer Study Group (2016) Timing of radiation therapy and chemotherapy after breastconserving surgery for node-positive breast cancer: long-term results from International Breast Cancer Study Group Trials VI and VII. Int J Radiat Oncol Biol Phys 96(2): 273-279.

Koh HK, Shin KH, Kim K, Lee ES, Park IH, Lee KS, Ro J, Jung SY, Lee S, Kim SW, Kang HS, Chie EK, Han W, Noh DY, Lee KH, Im SA, Ha SW (2016) Effect of time interval between breast-conserving surgery and radiation therapy on outcomes of node-positive breast cancer patients treated with adjuvant doxorubicin/cyclophosphamide followed by taxane. Cancer Res Treat 48(2): 483-490.
Kunkler IH, Williams LJ, Jack WJ, Cameron DA, Dixon JM, PRIME II investigators (2015) Breast-conserving surgery with or without irradiation in women aged 65 years or older with early breast cancer (PRIME II): a randomised controlled trial. Lancet Oncol 6(3): 266-273.

Livi L, Borghesi S, Saieva C, Meattini I, Rampini A, Petrucci A, Detti B, Bruni A, Paiar F, Mangoni M, Marrazzo L, Agresti B, Cataliotti L, Bianchi S, Biti G (2009) Radiotherapy Timing in 4820 Patients With Breast Cancer: University of Florence Experience. Int J Radiat Oncol Biol Phys 73(2): 365-369.

Mikeljevic JS, Haward R, Johnston C, Crellin A, Dodwell D, Jones A, Pisani P, Forman D (2004) Trends in postoperative radiotherapy delay and the effect on survival in breast cancer patients treated with conservation surgery. Br J Cancer 90(7): 1343-1348.

Moossdorff M, van Roozendaal LM, Strobbe LJ, Aebi S, Cameron DA, Dixon JM, Giuliano AE, Haffty BG, Hickey BE, Hudis CA, Klimberg VS, Koczwara B, Kühn T, Lippman ME, Lucci A, Piccart M, Smith BD, Tjan-Heijnen VCG, Van de Velde CJH, Van Zee KJ, Vermorken JB, Viale G, Voogd AC, Wapnir IL, White JR, Smidt ML (2014) Maastricht Delphi consensus on event definitions for classification of recurrence in breast cancer research. J Natl Cancer Inst 106(12): pii: dju288. doi:10.1093/ jnci/dju288.

Nationaal Borstkanker Overleg Nederland (NABON) (2012) Breast cancer. Available at: http://www.oncoline.nl/mammacarcinoom.

Olivotto IA, Lesperance ML, Truong PT, Nichol A, Berrang T, Tyldesley S, Germain F, Speers C, Wai E, Holloway C, Kwan W, Kennecke H (2009) Intervals longer than 20 weeks from breast-conserving surgery to radiation therapy are associated with inferior outcome for women with earlystage breast cancer who are not receiving chemotherapy. J Clin Oncol 27(1): 16-23.

Punglia RS, Morrow M, Winer EP, Harris JR (2007) Local therapy and survival in breast cancer. N Engl J Med 356(23): 2399-2405.

Rutgers EJTh, Nortier JWR, Tuut MK, Van Tienhoven G, Struikmans H, Bontenbal M, Von Meyenfeldt MF, Vreugdenhil G, Benraadt T, Garssen B, Peterse JL (2002) CBO-richtlijn 'Behandeling van het mammacarcinoom'. Ned Tijdschr Geneeskd 146: 2144-2151.

Shin DW, Cho J, Kim SY, Guallar E, Hwang SS, Cho B, Oh JH, Jung KW, Seo HG, Park JH (2013) Delay to curative surgery greater than 12 weeks is associated with increased mortality in patients with colorectal and breast cancer but not lung or thyroid cancer. Ann Surg Oncol 20(8): 2468-2476.

Sobin LH, Wittekind C (2002) TNM: classification of malignant tumours, 6th edition. Wiley: New York, USA.

Trufelli DC, Matos LL, Santi PX, Del Giglio A (2015) Adjuvant treatment delay in breast cancer patients. Rev Assoc Med Bras 61(5): 411-416.

Tsoutsou PG, Koukourakis MI, Azria D, Belkacemi Y (2009) Optimal timing for adjuvant radiation therapy in breast cancer: a comprehensive review and perspectives. Crit Rev Oncol Hematol 71(2): 102-116.

Vujovic O, Yu E, Cherian A, Dar AR, Stitt L, Perera F (2015) Time interval from breast-conserving surgery to breast irradiation in early stage nodenegative breast cancer: 17 -year follow-up results and patterns of recurrence. Int J Radiat Oncol Biol Phys 91(2): 319-324.

White IR, Royston P, Wood AM (2011) Multiple imputation using chained equations: Issues and guidance for practice. Stat Med 30(4): 377-399.

White IR, Royston P (2009) Imputing missing covariate values for the Cox model. Stat Med 28(15): 1982-1998.

This work is published under the standard license to publish agreement. After 12 months the work will become freely available and the license terms will switch to a Creative Commons AttributionNonCommercial-Share Alike 4.0 Unported License.

Supplementary Information accompanies this paper on British Journal of Cancer website (http://www.nature.com/bjc) 